\title{
EL DERECHO DE REUNIÓN DURANTE EL ESTADO DE ALARMA SANITARIA POR COVID-19
}

\author{
Miguel Ángel Presno Linera ${ }^{1}$ \\ Catedrático de Derecho Constitucional, \\ Universidad de Oviedo
}

Cómo citar este artículo / Citation: Presno Linera, M. A. (2021). El derecho de reunión durante el estado de alarma sanitaria por covid-19. Garrido López, C. (coord.)

Excepcionalidad y Derecho: el estado de alarma en España, Colección Obras colectivas, Fundación Manuel Giménez Abad, Zaragoza.

DOI: https://doi.org/10.47919/FMGA.OC21.0005

SUMARIO: I. PRESENTACIÓN. II. ESTADO DE ALARMA POR COVID-19 Y DERECHO DE REUNIÓN. III. EL AUTO DEL TRIBUNAL CONSTITUCIONAL 40/2020, DE 30 DE ABRIL. IV. LAS MANIFESTACIONES CONVOCADAS PARA EL 23 DE MAYO. V. BREVES CONSIDERACIONES SOBRE LA LIMITACIÓN DE LA PERMANENCIA DE GRUPOS DE PERSONAS EN ESPACIOS PÚBLICOS Y PRIVADOS DURANTE EL ESTADO DE ALARMA

\footnotetext{
${ }^{1}$ En el blog El derecho y el revés (https://presnolinera.wordpress.com/) he publicado diversos comentarios, desde el 8 de marzo de 2020, sobre la aplicación del Derecho de excepción a la crisis sanitaria del COVID-19; véanse, asimismo, las entradas de Francisco Velasco Caballero en su blog https://franciscovelascocaballeroblog.wordpress.com/ y las de Andrés Boix Palop en http://www.lapaginadefinitiva.com/author/andres-boix/ Es de gran interés el seguimiento realizado por ÁLVAREZ GARCÍA, ARIAS APARICIO y HERNÁNDEZ DÍEZ Lecciones jurídicas para la lucha contra una epidemia, lustel, Madrid, 2020; puede consultarse la información disponible en https://forocsyj.com/coronavirus-the-law/; con carácter general, es de gran utilidad toda la información recogida por el profesor Lorenzo COTINO HUESO en el Observatorio Derecho Público y Constitucional y Covid-19 (https://www.uv.es/derechos/): para una panorámica bibliográfica mucho más completa https://derechocovid.com/publicaciones-postcovid/ Para una perspectiva comparada son de gran interés las publicaciones disponibles en https://www.comparativecovidlaw.it/ y https://verfassungsblog.de/category/debates/covid-19and-states-of-emergency-debates/; centrados en la Unión Europea https://fra.europa.eu/en/themes/covid-19 y http://www.sidiblog.org/2020/03/24/forum-covid-19diritto-internazionale-e-diritto-dellunione-europea; en Ustados Unidos https://blogs.loc.gov/law/2020/03/coronavirus-resource-guide/?loclr=bloglaw; sobre Covid-19 y prisiones https://covid19prisons.wordpress.com/
} 


\section{PRESENTACIÓN}

Como es sabido, la Constitución española (CE) garantiza en su artículo 21 "el derecho de reunión pacífica y sin armas. El ejercicio de este derecho no necesitará autorización previa. En los casos de reuniones en lugares de tránsito público y manifestaciones se dará comunicación previa a la autoridad, que sólo podrá prohibirlas cuando existan razones fundadas de alteración del orden público, con peligro para personas o bienes". Enlaza, este precepto, en cierta medida, con lo previsto en el más amplio artículo 11 del Convenio Europeo de Derechos Humanos $(\mathrm{CEDH})^{2}$, y también guarda relación con el artículo 12 de la Carta de Derechos Fundamentales de la Unión Europea $(\text { CDFUE })^{3}$, aunque estos dos últimos preceptos incluyen, además, la libertad de asociación.

Hay que recordar, en esta breve presentación, la extraordinaria importancia de este derecho en un Estado democrático en la medida en que está estrechamente vinculado al ejercicio de la libertad de expresión; en este sentido, el Tribunal Europeo de Derechos Humanos (TEDH) tiene dicho que "la protección de las opiniones y la libertad de expresarlas es uno de los objetivos de las libertades de reunión y asociación recogidos en el artículo 11 (asunto Partido de Libertad y Democracia c. Turquía, de 8 de diciembre de 1991, § 37) $y$, al igual que aquellas, "la libertad de reunión como la recoge el artículo 11 del Convenio, protege una manifestación que moleste $u$ ofenda a las personas opuestas a las ideas o reivindicaciones que esté intentando conseguir" (asuntos Plataforma «Arzte für das Leben» c. Austria, de 21 de junio de 1988, $\S$ 32, y Stankov y United Macedonian Organisation Ilinden contra Bulgaria, de 2 de octubre de 2001, §§ 85 y 86).

\footnotetext{
2 "Toda persona tiene derecho a la libertad de reunión pacífica y a la libertad de asociación, incluido el derecho a fundar, con otras, sindicatos y de afiliarse a los mismos para la defensa de sus intereses. 2. El ejercicio de estos derechos no podrá ser objeto de otras restricciones que aquellas que, previstas por la ley, constituyan medidas necesarias, en una sociedad democrática, para la seguridad nacional, la seguridad pública, la defensa del orden y la prevención del delito, la protección de la salud o de la moral, o la protección de los derechos y libertades ajenos. El presente artículo no prohibe que se impongan restricciones legítimas al ejercicio de estos derechos por los miembros de las fuerzas armadas, de la policía o de la Administración del Estado".

3 "1. Toda persona tiene derecho a la libertad de reunión pacífica y a la libertad de asociación en todos los niveles, especialmente en los ámbitos político, sindical y cívico, lo que implica el derecho de toda persona a fundar con otras sindicatos y a afiliarse a los mismos para la defensa de sus intereses. 2. Los partidos políticos a escala de la Unión contribuyen a expresar la voluntad política de los ciudadanos de la Unión“.
} 
Las reuniones protegidas por el CEDH se definen por un determinado objetivo común de las personas participantes (Navalnyy c. Rusia, sentencia de la Gran Sala de 15 de noviembre de 2018, § 110), que puede tener un carácter esencialmente político, social, cultural, religioso...

La libertad de reunión incluye el derecho a elegir la hora, la fecha, el lugar y la forma de reunión, dentro de los límites establecidos por el artículo 11.2 (asunto Sáska c. Hungría, de 27 de noviembre de 2012, § 21). Por este motivo, en los casos en que el lugar de una reunión es de importancia crucial para los participantes, la orden procedente de la autoridad pública dirigida a modificarlo puede constituir una injerencia en el ejercicio del derecho (caso Lashmankin y otros c. Rusia, de 7 de febrero de 2017, § 405), si bien el derecho no incluye de forma automática la facultad de ejercerse en cualquier espacio de dominio público (Appleby y otros c. Reino Unido, de 6 de mayo de 2003, § 47), por lo que la prohibición de celebrar reuniones en determinados lugares y por motivos de seguridad no es incompatible con el artículo 11.

El derecho a la libertad de reunión pacífica entraña obligaciones tanto negativas como positivas para los Estados parte en el CEDH (Öllinger $c$. Austria, de 29 de junio de 2006, § 35), que no solo deben de abstenerse de imponer restricciones indebidas sino que también deben proteger ese derecho y es que, si bien el artículo 11 tiene por objeto esencialmente proteger a las personas contra la injerencia arbitraria de las autoridades públicas, también puede dar lugar a obligaciones positivas para garantizar el goce efectivo de esos derechos frente a otros (Kudrevičius y otros c. Lituania, sentencia de la Gran Cámara de 15 de octubre de 2015, § 158; Djavit An c. Turquía, de 20 de febrero de 2003, § 57). Y esa obligación positiva de garantizar el disfrute efectivo de la libertad de reunión reviste especial importancia para las personas cuyas opiniones son impopulares o que pertenecen a minorías, ya que son más vulnerables a la intimidación (Bączkowski y otros c. Polonia, de 3 de mayo de 2007, § 64).

Las autoridades internas tienen el deber de tomar las medidas necesarias para garantizar el buen desarrollo de cualquier manifestación legal y, al mismo tiempo, la seguridad de todos los ciudadanos, para lo que disponen de un amplio margen de discrecionalidad en la elección del método a utilizar. En particular, el TEDH ha subrayado la importancia de las medidas de seguridad preventivas, con el fin de garantizar el buen desarrollo de las manifestaciones, 
reuniones o encuentros, ya sean políticos, culturales o de otro tipo (Oya Ataman c. Turquía, de 5 de diciembre de 2006, § 39).

Como la gran mayoría de derechos, también el de reunión está sometido a restricciones que, no obstante, y de acuerdo con el artículo 11.2 CEDH, deben estar por la ley y ser medidas necesarias, en una sociedad democrática, para la seguridad nacional, la seguridad pública, la defensa del orden y la prevención del delito, la protección de la salud o de la moral, o la protección de los derechos y libertades ajenos.

Las medidas limitativas del derecho deben responder a una "necesidad social apremiante" y ser proporcionadas al "objetivo legítimo", y las razones invocadas por las autoridades nacionales para justificarlas deben ser "pertinentes y suficientes". Además, hay que distinguir las restricciones al derecho de reunión basadas en el contenido de las que tiene una naturaleza técnica.

En cuanto a las primeras, el artículo 11 garantiza una fuerte protección a las manifestaciones públicas que forman parte de la vida política nacional o local y hay pocas situaciones en las que se pueda prohibir legítimamente una reunión sobre la base de la sustancia del mensaje que los participantes se proponen transmitir: las autoridades no deben contar con la facultad de prohibir una manifestación basándose en considerar el "mensaje" de los manifestantes como erróneo o inadecuado, especialmente cuando es el facultado para limitar o prohibir la reunión pública en cuestión el que está principalmente en el punto de mira de los críticos. EI TEDH somete las restricciones de la libertad de reunión basadas en el contenido al control más estricto (caso Navalnyy c. Rusia, ya citado § 134; Primov y otros c. Rusia, de 12 de junio de 2014, §§ 134135). Y es que, en una sociedad democrática basada en el Estado de derecho, las ideas que desafían el orden establecido y cuya realización se defiende por medios pacíficos deben tener la oportunidad adecuada de expresarse mediante el ejercicio de la libertad de reunión y otros medios lícitos (Stankov y Organización Macedonia Unida Ilinden c. Bulgaria, de 2 de octubre de 2001, 97; Sergei Kuznetsov c. Rusia, de 23 de octubre de 2008, § 45).

Respecto a las segundas, una prohibición general de las manifestaciones sólo puede justificarse si existe un riesgo real de que den lugar a disturbios que no puedan evitarse con otras medidas menos estrictas. $\mathrm{Y}$ el TEDH ha reiterado que la injerencia en el ejercicio de la libertad de reunión pacífica no tiene por qué equivaler a una prohibición absoluta, legal o de facto, sino que puede 
fundación

Manuel Giménez Abad

deEstudios ParlamentariosydelEstado Autonómico

consistir en otras medidas diversas adoptadas por las autoridades (asunto Laguna Guzmán c. España, de 6 de octubre de 2020, § 40).

En una línea coincidente con esta jurisprudencia europea, el Tribunal Constitucional (STC 193/2011, de 12 de diciembre, FJ 3), también ha insistido en que "el derecho de reunión -del que el derecho de manifestación es una vertiente (STC 96/2010, de 15 de noviembre, FJ 3)- se caracteriza como "una manifestación colectiva de la libertad de expresión efectuada a través de una asociación transitoria de personas que opera de manera instrumental al servicio del intercambio o exposición de ideas, de defensa de intereses o de publicidad de problemas y reivindicaciones, cuyos elementos configuradores son el subjetivo (agrupación de personas), el temporal (duración transitoria), el finalista (licitud de la finalidad) y el real u objetivo (lugar de celebración)" (STC 85/1988, de 28 de abril, FJ 2; doctrina reiterada, entre otras, en las SSTC 66/1995, de 8 de mayo, FJ 3; 196/2002, de 28 de octubre, FJ 4; 301/2006, de 23 de octubre, FJ 2; 170/2008, de 15 de diciembre, FJ 3 y 38/2009, de 9 de febrero, FJ 2). Existe, pues, una estrecha vinculación entre el derecho de reunión y manifestación y el derecho a la libre expresión... El derecho de reunión se convierte, así, en uno de los ejes vertebradores (cauce del principio democrático participativo) del Estado social y democrático de Derecho proclamado en la Constitución, cuyo contenido, sin embargo, puede verse modulado por los límites a su ejercicio que forzosamente impone la protección de otros bienes o derechos constitucionales".

Finalmente, el derecho fundamental de reunión es, de conformidad con el artículo 55.1 CE, susceptible de ser suspendido "cuando se acuerde la declaración del estado de excepción o de sitio en los términos previstos en la Constitución", lo que excluye, como es obvio, su suspensión en los supuestos de declaración del estado de alarma. Ahora bien, este derecho, como la inmensa mayoría, no es absoluto o ilimitado, "sino que, al igual que los demás derechos fundamentales, puede verse sometido a ciertas modulaciones 0 límites, entre los que se encuentran tanto el específicamente previsto en el propio art. 21.2 CE -alteración del orden público con peligro para personas y bienes-, como aquellos otros que vienen impuestos por la necesidad de evitar que un ejercicio extralimitado del derecho pueda entrar en colisión con otros valores constitucionales (STC 42/2000, de 14 de febrero, FJ 2). Límites que, como recordábamos en la STC 195/2003, de 27 de octubre, (FJ 7), y todas las que allí se citan, han de ser necesarios "para conseguir el fin perseguido 
debiendo atender a la proporcionalidad entre el sacrificio del derecho y la situación en la que se halla aquel a quien se impone... y, en todo caso, respetar su contenido esencial" (STC 193/2012, FJ 3).

\section{ESTADO DE ALARMA POR COVID-19 Y DERECHO DE REUNIÓN}

Como es bien sabido, el 14 de marzo de 2020 se aprobó el Real Decreto 463/2020 "por el que se declara el estado de alarma para la gestión de la situación de crisis sanitaria ocasionada por el COVID-19". En su Exposición de Motivos se dice, entre otras cosas, que las medidas acordadas se orientan a "proteger la salud y seguridad de los ciudadanos, contener la progresión de la enfermedad y reforzar el sistema de salud pública... Las medidas que se contienen en el presente real decreto son las imprescindibles para hacer frente a la situación, resultan proporcionadas a la extrema gravedad de la misma y no suponen la suspensión de ningún derecho fundamental, tal y como prevé el artículo 55 de la Constitución".

Por lo que aquí interesa ahora, las previsiones más relevantes son las contenidas en el artículo 7 del citado Real Decreto 463/2020:

"Durante la vigencia del estado de alarma las personas únicamente podrán circular por las vías de uso público para la realización de las siguientes actividades:

a) Adquisición de alimentos, productos farmacéuticos y de primera necesidad.

b) Asistencia a centros, servicios y establecimientos sanitarios.

c) Desplazamiento al lugar de trabajo para efectuar su prestación laboral, profesional o empresarial.

d) Retorno al lugar de residencia habitual.

e) Asistencia y cuidado a mayores, menores, dependientes, personas con discapacidad o personas especialmente vulnerables.

f) Desplazamiento a entidades financieras y de seguros.

g) Por causa de fuerza mayor o situación de necesidad. 
h) Cualquier otra actividad de análoga naturaleza que habrá de hacerse individualmente, salvo que se acompañe a personas con discapacidad o por otra causa justificada.

2. Igualmente, se permitirá la circulación de vehículos particulares por las vías de uso público para la realización de las actividades referidas en el apartado anterior o para el repostaje en gasolineras o estaciones de servicio.

3. En todo caso, en cualquier desplazamiento deberán respetarse las recomendaciones y obligaciones dictadas por las autoridades sanitarias.

4. El Ministro del Interior podrá acordar el cierre a la circulación de carreteras o tramos de ellas por razones de salud pública, seguridad o fluidez del tráfico o la restricción en ellas del acceso de determinados vehículos por los mismos motivos.

Cuando las medidas a las que se refieren los párrafos anteriores se adopten de oficio se informará previamente a las administraciones autonómicas que ejercen competencias de ejecución de la legislación del Estado en materia de tráfico, circulación de vehículos y seguridad vial.

Las autoridades estatales, autonómicas y locales competentes en materia de tráfico, circulación de vehículos y seguridad vial garantizarán la divulgación entre la población de las medidas que puedan afectar al tráfico rodado".

Como se puede leer, el derecho fundamental sometido a limitación -dando por supuesto que, efectivamente, se produce una mera limitación del derecho ${ }^{4}$ - es

\footnotetext{
${ }^{4}$ A nuestro juicio, la Ley Orgánica 4/1981 optó, pudiendo hacer otra cosa, por medidas que parecen menos gravosas que las realmente adoptadas bajo su amparo en el Decreto 463/2020. El juicio de proporcionalidad sobre las mismas (que la medida limitativa sea adecuada o idónea para la consecución del fin perseguido; que sea la mínima imprescindible para tal finalidad y que haya proporcionalidad entre el sacrificio exigido al derecho limitado por esa medida y el concreto derecho, bien o interés que se pretende proteger) no puede hacerse al margen de los propios límites que ha preestablecido el legislador orgánico.

No entramos a cuestionar aquí si esas medidas limitativas de la libertad de circulación son, o no, las mejores para contener la epidemia, al margen de que en otros países no hayan alcanzado la misma intensidad. Pero, además de aplicarse de forma razonada y razonable, "deben fundarse en una Ley" y nos parece discutible que en el caso que nos ocupa tengan un fundamento claro en la L. O. 4/1981, máxime teniendo en cuenta que debe interpretarse la normativa aplicable en el sentido más favorable para la efectividad de los derechos fundamentales (Sentencia del Tribunal Constitucional 17/1985, de 5 de marzo, FJ 4); al respecto, en términos generales, REQUEJO RODRÍGUEZ, P. "La suspensión de los derechos fundamentales", en BASTIDA FREIJEDO y otros, Teoría general de los derechos 
la libertad de circulación, pero no la libertad de reunión cuya afectación como tal derecho no está contemplada en el artículo 11 de la Ley Orgánica 4/1981, de 1 de junio, de los estados de alarma, excepción y sitio, que, para lo que aquí y ahora interesa, únicamente prevé que "el decreto de declaración del estado de alarma, o los sucesivos que durante su vigencia se dicten, podrán acordar...

a) Limitar la circulación o permanencia de personas o vehículos en horas y lugares determinados, o condicionarlas al cumplimiento de ciertos requisitos".

A este respecto, en el Real Decreto 926/2020, de 25 de octubre, por el que se declara el estado de alarma para contener la propagación de infecciones causadas por el SARS-CoV-2, prevé, expresamente, que "las reuniones en lugares de tránsito público y las manifestaciones realizadas en ejercicio del derecho fundamental regulado en el artículo 21 de la Constitución podrán limitarse, condicionarse o prohibirse cuando en la previa comunicación presentada por los promotores no quede garantizada la distancia personal necesaria para impedir los contagios" (artículo 7.3). Es decir, ya se dice claramente que, con carácter general, no está limitado el derecho de reunión ${ }^{5}$.

fundamentales en la Constitución española de 1978, Tecnos, Madrid, 2004, págs. 222-235; sobre esta cuestión y las diferentes posturas doctrinales en relación con el estado de alarma declarado por el Decreto 463/2020, GARRIDO LÓPEZ, C. "La naturaleza bifronte del estado de alarma y el dilema limitación-suspensión de derechos", Teoría y Realidad Constitucional, núm. 46, 2020, pp. 371-402; véanse también COTINO HUESO, L. "Los derechos fundamentales en tiempos del coronavirus. Régimen general y garantías y especial atención a las restricciones de excepcionalidad ordinaria" en El Cronista del Estado Social y Democrático de Derecho "Coronavirus... y otros problemas, 86/87, 2020, pp. 88-101; COTINO HUESO, L. "Confinamientos, libertad de circulación y personal, prohibición de reuniones y actividades y otras restricciones de derechos por la pandemia del Coronavirus" en Diario La Ley, núm. 9608, Sección Doctrina; SANTAMARÍA PASTOR J. A. "Notas sobre el ejercicio de las potestades normativas en tiempos de pandemia", en BLANQUER CRIADO, D. COVID-19 y Derecho Público (durante el estado de alarma y más allá), Tirant lo Blanch, Valencia, 2020, pp. 207-240; SOLOZABAL ECHAVARRÍA, J. J. "Algunas consideraciones constitucionales sobre el estado de alarma" en BIGLINO CAMPOS, P. y DURÁN ALBA, J. F. Los Efectos Horizontales de la COVID sobre el sistema constitucional, Colección Obras colectivas, Fundación Manuel Giménez Abad, Zaragoza, 2020, https://doi.org/10.47919/FMGA.OC20.0002.

${ }_{5}^{5}$ Sobre esta cuestión, y a propósito del estado de alarma declarado por el Decreto 463/2020, de 14 de marzo, pueden verse los estudios de ARNALDO ALCUBILLA, E. "Salus populi est lex, sed lex superior est constitutio. El ejercicio del derecho de manifestación en el estado de alarma", Diario La Ley, núm. 9645, 19 de mayo de 2020; BILBAO UBILLOS, J. M. "La libertad de reunión y manifestación en tiempos de pandemia" en BIGLINO CAMPOS, P. y DURÁN ALBA, J. F. (Dirs.), Los efectos horizontales de la COVID sobre el sistema constitucional, Colección Obras colectivas, Zaragoza: Fundación Manuel Giménez Abad, Zaragoza. DOI: https://doi.org/10.47919/FMGA.OC20.0013; COTINO HUESO, L. "Confinamientos, libertad de circulación y personal, prohibición de reuniones y actividades y otras restricciones de derechos por la pandemia del Coronavirus" en Diario La Ley, núm. 9608, Sección Doctrina; ITURENOLIVER, A./ESTEVE-SEGARRA, A. "El ejercicio del derecho de manifestación (sindical o no) durante la pandemia por el COVID-19", Trabajo y Derecho. Monográfico 12/2020, núm. 12, 2020; RODRÍGUEZ-PIÑERO y BRAVO-FERRER, M. "Estado de alarma y derecho de manifestación del sindicato", Derecho de las relaciones laborales, núm. 6, pp. 673-774. 
$Y$ es que, como parece evidente, durante la vigencia de los estados de alarma sigue operando el resto del ordenamiento constitucional -el artículo 116.1 CE dispone que "la declaración de los estados de alarma, de excepción y de sitio no modificarán el principio de responsabilidad del Gobierno y de sus agentes reconocidos en la Constitución y en las leyes" y el propio artículo 4.1 de la L.O. 4/1981 prevé que "la declaración de los estados de alarma, excepción y sitio no interrumpe el normal funcionamiento de los poderes constitucionales del Estado- y, en lo que afecta al derecho de reunión, la misma CE -artículo 21.2: "En los casos de reuniones en lugares de tránsito público y manifestaciones se dará comunicación previa a la autoridad, que sólo podrá prohibirlas cuando existan razones fundadas de alteración del orden público, con peligro para personas o bienes"- y la Ley Orgánica 9/1983, de 15 de julio, reguladora del derecho de reunión, cuyo artículo 10 establece que "si la autoridad gubernativa considerase que existen razones fundadas de que puedan producirse alteraciones del orden público, con peligro para personas o bienes, podrá prohibir la reunión o manifestación o, en su caso, proponer la modificación de la fecha, lugar, duración o itinerario de la reunión o manifestación".

A este respecto, también existe una doctrina jurisprudencial consolidada, de la que es buena prueba la ya citada STC 193/2011, de 12 de diciembre; en el mismo FJ 3 se puede leer, recogiendo sentencias anteriores, que:

“... el derecho recogido en el art. 21 CE no es un derecho absoluto o ilimitado, sino que, al igual que los demás derechos fundamentales, puede verse sometido a ciertas modulaciones o límites, entre los que se encuentran tanto el específicamente previsto en el propio art. 21.2 CE alteración del orden público con peligro para personas y bienes-, como aquellos otros que vienen impuestos por la necesidad de evitar que un ejercicio extralimitado del derecho pueda entrar en colisión con otros valores constitucionales" (STC 42/2000, de 14 de febrero, FJ 2). Límites que, como recordábamos en la STC 195/2003, de 27 de octubre, (FJ 7), y todas las que allí se citan, han de ser necesarios "para conseguir el fin perseguido debiendo atender a la proporcionalidad entre el sacrificio del derecho y la situación en la que se halla aquel a quien se impone ... y, en todo caso, respetar su contenido esencial". 
Por ello, la limitación del ejercicio del derecho de reunión requiere de una motivación específica. Así, "para que los poderes públicos puedan incidir en el derecho de reunión constitucionalmente garantizado, ya sea restringiéndolo, modificando las circunstancias de su ejercicio, o prohibiéndolo incluso, es preciso, tal y como acaba de señalarse, que existan razones fundadas, lo que implica una exigencia de motivación de la resolución correspondiente ... en la que se aporten las razones que han llevado a la autoridad gubernativa a concluir que el ejercicio del derecho fundamental de reunión, tal y como se hubo proyectado por su promotor o sus promotores, producirá una alteración del orden público proscrita en el art. 21.2 CE, o bien la desproporcionada perturbación de otros bienes o derechos protegidos por nuestra Constitución" (STC 195/2003, de 27 de octubre, FJ 4). Y en este sentido "no basta con que existan dudas sobre si el derecho de reunión pudiera producir efectos negativos, debiendo presidir toda actuación limitativa del mismo el principio o criterio de favorecimiento del derecho de reunión ... de manera que solamente razones convincentes e imperativas pueden justificar las restricciones a esa libertad (STC 170/2008, FJ 3)" (STC 96/2010, de 15 de noviembre, FJ 3, relativa al ejercicio del derecho de manifestación durante la jornada de reflexión), en aplicación del principio favor libertatis. Los actos que introduzcan medidas limitadoras han de fundamentarse, pues, en datos objetivos suficientes derivados de las circunstancias concretas de cada caso (STC 301/2006, 23 de octubre, FJ 2)".

Por tanto, y con carácter general, durante la vigencia del estado de alarma, por cualquiera de los motivos que contempla la L. O. 4/1981 en su artículo 46 , y ante la notificación de que se va a celebrar una reunión o una manifestación, cabría que, por parte de la autoridad administrativa competente, se acordara alguna de las medidas previstas en el artículo 10 de la L. O. 9/1983: “... prohibir

\footnotetext{
6 "El Gobierno, en uso de las facultades que le otorga el artículo ciento dieciséis, dos, de la Constitución podrá declarar el estado de alarma, en todo o parte del territorio nacional, cuando se produzca alguna de las siguientes alteraciones graves de la normalidad:

a) Catástrofes, calamidades o desgracias públicas, tales como terremotos, inundaciones, incendios urbanos y forestales o accidentes de gran magnitud.

b) Crisis sanitarias, tales como epidemias y situaciones de contaminación graves.

c) Paralización de servicios públicos esenciales para la comunidad, cuando no se garantice lo dispuesto en los artículos veintiocho, dos, y treinta y siete, dos, de la Constitución, concurra alguna de las demás circunstancias o situaciones contenidas en este artículo.

d) Situaciones de desabastecimiento de productos de primera necesidad".
} 
la reunión o manifestación o, en su caso, proponer la modificación de la fecha, lugar, duración o itinerario de la reunión o manifestación" y ello con el objetivo de "evitar que un ejercicio extralimitado del derecho pueda entrar en colisión con otros valores constitucionales" (STC 42/2000, de 14 de febrero, FJ 2).

Para ello, como ya se ha apuntado, es preciso que "existan razones fundadas, lo que implica una exigencia de motivación de la resolución correspondiente ... en la que se aporten las razones que han llevado a la autoridad gubernativa a concluir que el ejercicio del derecho fundamental de reunión, tal y como se hubo proyectado por su promotor o sus promotores, producirá una alteración del orden público proscrita en el art. 21.2 CE, o bien la desproporcionada perturbación de otros bienes o derechos protegidos por nuestra Constitución" (STC 195/2003, de 27 de octubre, FJ 4).

EI TC ha añadido, en relación a la existencia de "razones fundadas", que no basta la mera sospecha o la posibilidad sino que "quien adopta esta decisión debe poseer datos objetivos suficientes, derivados de las circunstancias de hecho concurrentes en cada caso, a partir de los que cualquier persona en una situación normal pueda llegar racionalmente a la conclusión, a través de un proceso lógico basado en criterios de experiencia, que la concentración producirá con toda certeza el referido desorden público — naturalmente, con toda la certeza o la seguridad que puede exigirse a un razonamiento prospectivo aplicado al campo del comportamiento humano. En cualquier caso... si existen dudas sobre la producción de estos efectos, una interpretación sistemática del precepto constitucional lleva a la necesaria aplicación del principio de favor libertatis y a la consiguiente imposibilidad de prohibir la realización de la concentración" (STC 163/2006, de 22 de mayo, FJ 2).

$\mathrm{Y}$, en lo que respecta a la proporcionalidad de las medidas a adoptar por la autoridad administrativa, en la misma STC 163/2006, se advierte que dicha autoridad debe arbitrar las

"adecuadas para garantizar que las concentraciones puedan llevarse a cabo en los lugares y horas programados sin poner en peligro el orden público; desviando, por ejemplo, el tráfico por otras vías o prohibiendo la ocupación prolongada de las calzadas y disponiendo los instrumentos necesarios para hacer efectiva tal prohibición. Sólo podrá restringirse el ejercicio del derecho de reunión cuando estas medidas preventivas 
resulten imposibles de adoptar, o sean infructuosas para alcanzar el fin propuesto -por ejemplo porque no permitan hacer accesible la zona afectada-, o sean desproporcionadas -por ejemplo, cuando los posibles itinerarios alternativos supongan retrasos o rodeos irrazonables.

... incluso en los supuestos en los que existan razones fundadas de que una concentración puede producir alteraciones del orden público con peligro para personas y bienes, la autoridad gubernativa, aplicando criterios de proporcionalidad, antes de prohibirla deberá utilizar, si ello es posible, la facultad que le reconoce el art. 10 de la Ley Orgánica 9/1983 y proponer las modificaciones de fecha, lugar o duración al objeto de que la reunión pueda celebrarse.

Es esta última, sin embargo, una facultad que la Administración no puede ejercer de forma totalmente discrecional (STC 36/1982), y que viene condicionada por la programación realizada por los promotores. Esto hará que, en ocasiones, la utilización de esta facultad de introducir modificaciones resulte vedada 0 , cuando menos, sometida a importantes condicionamientos. Por ejemplo, respecto a las alteraciones relativas al lugar de concentración o manifestación, la autoridad gubernativa deberá tener presente que este elemento objetivo configurador del derecho de reunión tiene en la práctica un relieve fundamental ya que está íntimamente relacionado con el objetivo de publicidad de las opiniones y reivindicaciones perseguido por los promotores por lo que ese emplazamiento condiciona el efectivo ejercicio del derecho. En realidad, en ciertos tipos de concentraciones el lugar de celebración es para los organizadores la condición necesaria para poder ejercer su derecho de reunión en lugares de tránsito público, puesto que del espacio físico en el que se desenvuelve la reunión depende que el mensaje que se quiere transmitir llegue directamente a sus destinatarios principales. Esto acontece, por ejemplo, en los supuestos en los que los reunidos pretenden hacer llegar sus opiniones o sus reivindicaciones, no sólo a la opinión pública en general o a los medios de comunicación, sino muy particularmente a determinadas entidades 0 , mejor, a determinadas personas que ocupan cargos en las mismas. La posibilidad de realizar la concentración en un lugar próximo a la sede de las entidades afectadas y en un horario de trabajo se convierte, en estos casos, en factores determinantes a la hora de ejercer el derecho de reunión. Naturalmente, 
de ello no se infiere que, en estos supuestos, este tipo de concentraciones siempre deba poder celebrarse en los lugares programados por los organizadores, pero sí puede influir, como veremos, en la facultad de ofrecer alternativas por parte de la autoridad gubernativa.

Es más, incluso en los casos en los que los reunidos no pretendan comunicar sus opiniones a unos destinatarios específicos sino a la opinión pública en general, el lugar de la concentración no puede considerarse en absoluto indiferente $y$, en consecuencia, tampoco cabe hablar de discrecionalidad de la Administración al ofrecer lugares alternativos. Con ello no se trata sólo de afirmar que el lugar propuesto debe tener suficiente tránsito público como para garantizar la publicidad que constituye uno de los elementos esenciales del contenido del derecho, sino que ese lugar debe garantizar una repercusión pública -en número y características de los destinatarios, es decir, de quienes pueden tener noticia de la reunión, incluidos los medios de comunicación- que se aproxime al máximo a la que pretendían alcanzar los promotores en el lugar por ellos programado" (FJ 3).

Pues bien, la anteriormente expuesta línea argumental es la que siguió la Sección Primera de la Sala de lo Contencioso-administrativo del Tribunal Superior de Justicia (TSJ) de Aragón en su sentencia 151/2020, de 30 de abril, en la que resolvió el recurso interpuesto por la Intersindical de Aragón contra la resolución de la Subdelegación del Gobierno en Zaragoza de 22 de abril de 2020 en la que acordó prohibir la celebración de una manifestación comunicada para el 1 de mayo de $2020^{7}$.

En la sentencia, luego de descartar la limitación del derecho de reunión durante la vigencia del estado de alarma, así como también el planteamiento de una cuestión de inconstitucionalidad propuesto por uno de los magistrados de la Sección a propósito del contenido del artículo 7 del Decreto 463/2020, el TSJ sostuvo, a nuestro juicio con buen criterio, que lo que "debe explicar la Administración al prohibir la manifestación en cuestión, más allá de invocar de manera genérica la necesidad de combatir la pandemia, es en qué medida, en

\footnotetext{
${ }^{7}$ Véanse los comentarios a esta resolución de ARNALDO ALCUBILLA, E. "Salus populi est lex, sed lex superior est constitutio. El ejercicio del derecho de manifestación en el estado de alarma", Diario La Ley... pp. 3 y ss., y BILBAO UBILLOS, J. M. "La libertad de reunión y manifestación en tiempos de pandemia" en BIGLINO CAMPOS, P. y DURÁN ALBA, J. F. (Dirs.), Los efectos horizontales de la COVID sobre el sistema constitucional,... p. 4.
} 
el caso concreto, limitada la participación a sesenta personas y todos ellos en vehículos individuales, puede suponer un riesgo objetivo y cierto de contagio y propagación de la enfermedad y esto es lo que no hace" (FJ 5). A continuación, el TSJ dice:

"Antes bien, la Administración sostiene su decisión en dos valoraciones genéricas que son dos conjeturas. La primera es que "en las circunstancias actuales, es un hecho notorio que es completamente seguro que se produzcan contagios entre las personas participantes que luego puedan extenderse entre sus círculos de amistad, profesionales y familiares, incrementando de esta manera la crisis sanitaria por más que se adopten medidas de seguridad". Tal enunciado genérico se hace sin contrastarlo con el modo de manifestación propuesto, según el cual se hará en coche, con una persona por coche, y con motocicletas o bicicletas. No se explica cómo han de producirse, si cada uno va con la protección prevista, seguros casos de contagio... Es decir, ni se ha justificado una afirmación tan categórica, según la cual de nada servirían los elementos de protección, ni, ante una afirmación tan rotunda, se ha propuesto una alternativa.

En cuanto a la afirmación de que podría haber problemas de orden público por parte del resto de los ciudadanos, confinados, es una mera conjetura. De hecho, ante un confinamiento masivo de cuarenta y cinco millones de personas, el comportamiento ciudadano global ha sido ejemplar, con únicamente incidencias aisladas. En cualquier caso, precisamente para garantizar el libre y seguro ejercicio de los derechos fundamentales del ciudadano están los Poderes Públicos, en general, y las Fuerzas y Cuerpos de Seguridad del Estado, en particular.

Por tanto, y como decíamos más arriba, en el caso concreto la Administración se ha limitado a prohibir, sin hacer propuesta alguna de modificación o de imposición de condiciones y sin motivar con base en argumentos contrastados la inadecuación de la propuesta realizada, más allá de formular dos conjeturas ayunas de sostén probatorio y de contraste con la concreta solicitud realizada".

El TSJ concluyó, creemos que, con razón, anulando la resolución administrativa recurrida y declarando procedente la comunicación de manifestación por la entidad recurrente, organizada para el día Primero de 
Mayo, en las condiciones declaradas por dicha entidad: "participación de sesenta ciudadanos, en vehículo particular, cubierto, turismo, con un único ocupante en cada uno, sin que sea admisible la participación en otro tipo de vehículo no cubierto, esto es, motocicleta o bicicleta..." (FJ 6).

En la misma línea, el TSJ de Navarra, en la sentencia 69/2020, de 30 de abril, estimó (FJ 5ํ) que "considerar el contexto de la actual crisis sanitaria existente, no puede significar que la Autoridad competente impida absolutamente el ejercicio de derecho de reunión. Dicho de otro modo, no puede llevar a la Administración, en la práctica, en todo caso, y de plano, a la denegación de la concentración estática y reducida que nos ocupa, so pena de dejar el derecho de reunión vacío de contenido; lo que se deduce de la resolución administrativa es que, habida cuenta de que existe decretado estado de alarma, en ningún caso se podría autorizar una manifestación. Se concluye en la tesis de la parte demandada, y así se expresó en la vista, que el derecho de manifestación y reunión no está suspendido, pero que en la práctica no puede ejercerse en ningún caso debido a la pandemia. Esta Sala no comparte esta tesis porque se ha decidir en atención al contexto señalado, sí, pero también a la luz de la CE cuya aplicación no ha sido desplazada ni suspendida durante el estado de alarma... si hay peligro de contagio como parece defender la Delegación del Gobierno hay que justificarlo debidamente ponderando y valorando de modo suficiente las circunstancias concurrentes...".

La sentencia concluye (FJ 6을 que:

“... ha de estimar el recurso, en tanto que la Administración, al socaire del estado de alarma, niega en todo caso el ejercicio del derecho de reunión, y no pondera ad casum la reducción al mínimo de los riesgos sanitarios que se podrían producir, a la vista, precisamente del diseño de concentración para la que se hace la comunicación y que ahora nos ocupa.

La concentración solicitada, en los términos comunicados, es estática (tanto en su preparación como en su desarrollo y en su ejecución posterior), es corta en el tiempo y es cuantitativamente reducida en su participación pudiéndose controlar de manera efectiva (en términos de control del orden público por la Autoridad en su preparación y desarrollo) las medidas de seguridad ofrecidas y las exigidas por la Autoridades Sanitarias de cumplimiento obligatorio. Todo ello va a determinar la 
revocación de la prohibición de la concentración solicitada dado en que la misma, por sus características concretas ya expuestas, no reviste ni supone alteración fundada del orden público (entendido como ha hecho el TC como desorden material que impidan la convivencia ciudadana con afectación de la integridad física o moral de las personas o bienes STC $66 / 1995)$ sin razones fundadas de peligro actual para la salud de las personas (art 21.2.CE)",

\footnotetext{
${ }^{8}$ No obstante, y por ser otras las condiciones en las que se pretendía ejercer el derecho fundamental de reunión, este mismo TSJ, en la sentencia 70/2020, de 30 de abril, concluyó (FJ $5^{\circ}$ ) que "atendidas las circunstancias del caso que nos ocupa, la propuesta de manifestación, como motiva la administración, no está exenta de riesgos para la salud de las personas, lo que puede justificar limitaciones al citado derecho fundamental. Es preciso recordar que, a diferencia de lo que manifiesta el sindicato recurrente no es exigible la certeza de que se van a producir contagios por la interactuación de participantes entre sí o con terceros, sino que basta un peligro fundado y apreciable para las personas. La manifestación solicitada, en los términos comunicados, es dinámica (alguna de las solicitadas incluso se desarrolla incursionando entre distintos municipios) tanto en su preparación como en su desarrollo y en su ejecución posterior; es amplia en el tiempo y cuantitativamente significativa en su participación sin que puedan ser controlables de manera efectiva (en términos de control del orden público por la Autoridad en su preparación y desarrollo) las medidas de seguridad ofrecidas y las exigidas por la Autoridades Sanitarias de cumplimiento obligatorio que permitan soslayar fundadamente la alteración del orden público con peligro para la salud de las personas. Todo ello determina la prohibición de la manifestación solicitada dado en que la misma, por sus características concretas ya expuestas, existen fundadas razones de alteración del orden público (entendido como ha hecho el TC como desorden material que impida la convivencia ciudadana con afectación de la integridad física o moral de las personas o bienes STC 66/1995) con peligro actual para la salud de las personas (art 21.2.CE) derivada de la pandemia Covid-19 que padecemos...

Así en este caso, existe, como aprecia Delegación del Gobierno riesgo de interacción entre los participantes, que no son un número reducido sino 20 por cada una de las cuatro convocatorias previstas y de estos, a su vez, con las personas que en cada delegación territorial del sindicato, van a preparar, suministrar y recogen la cartelería que se pretende utilizar. Esa interacción es fácilmente previsible previamente durante la reunión de los vehículos para la salida, la organización e inicio de la marcha estableciendo el orden para ello, en el desarrollo de la misma por razón de las propias circunstancias del uso de vehículos a motor -piénsese en una avería por ejemplo-, así como en la finalización para disolverla.

La duración de la marcha, de hora y media, ratifica la posibilidad de que las interactuaciones se produzcan en su desarrollo al ser un lapso de tiempo notable. El uso del material sanitario o el mantenimiento de la distancia social no se puede asegurar en todo momento y, en todo caso, no va a poder ser controlado por las Fuerzas de Seguridad, en los términos que se han expuesto ut supra. Esta imposibilidad de control es especialmente intensa en el momento de la preparación, entrega y recogida de carteles, pues si bien el sindicato señala que se realizarán sin contacto entre personas y con uso de mascarillas, geles y guantes, son actividades que se van a producir en el interior de las sedes del sindicato.

Así mismo, el uso de vehículos a motor no disminuye el riesgo de contagio sino que puede incluso incrementarlo, puesto que los vehículos son vectores del Covid-19, habiéndose vuelto necesarias, precisamente por este motivo, las labores de desinfección tanto de calles como especialmente de aquellos vehículos que recorren diversas localidades por prestar servicios públicos o esenciales. En este caso el riesgo es evidente atendido el número de vehículos que se van a mover, la duración de la caravana reivindicativa y es especialmente intenso en el caso de la marcha prevista para Sakana, con entrada y recorrido de cinco localidades (Etxarri Aranaz, Bakaiku, Iturmendi, Urdiain y Alsasua) sin haberse si quiera propuesto medidas de desinfección de los turismos.
} 
III. EL AUTO DEL TRIBUNAL CONSTITUCIONAL 40/2020, DE 30 DE ABRIL

El mismo día que las citadas sentencias de los TSJ de Aragón y Navarra se conoció el Auto del Tribunal Constitucional (ATC) 40/2020, que inadmitió a trámite el recurso de amparo promovido por la Central Unitaria de Traballadores/as (CUT) contra la sentencia 136/2020 de la Sección Primera de la Sala de lo Contencioso-administrativo del Tribunal Superior de Xustiza de Galicia, dictada en el procedimiento Derecho de reunión 152-2020, y contra la resolución de 21 de abril de 2020 de la Subdelegación del Gobierno de Pontevedra en relación con la comunicación de la celebración de una manifestación el 1 de mayo de 2020 en Vigo ${ }^{9}$.

Se trata de la primera, y hasta ahora única, resolución del TC vinculada a la declaración del estado de alarma y lo primero que llama la atención es que se trata de un Auto de inadmisión que se parece mucho en su extensión (los fundamentos jurídicos ocupan 15 páginas) y, sobre todo en sus argumentos, a lo que podría ser una sentencia desestimatoria de un recurso de amparo previamente admitido a trámite ${ }^{10}$. El argumento que justifica este proceder es que, como dice el TC (FJ 3):

"admitida la especial trascendencia constitucional del asunto que nos ocupa, y atendiendo a la premura que exige su resolución, habida cuenta de que la viabilidad del ejercicio del derecho, en su caso,

En definitiva, la Administración razona y motiva suficientemente la prohibición de la caravana de coches pretendida por la parte actora en ejercicio de su derecho de manifestación, atendido el riesgo para la salud de las personas derivado del ejercicio propuesto."

${ }^{9}$ En los antecedentes se nos informa que "el motivo de la convocatoria es celebrar el día 1 de mayo, de la clase trabajadora... La manifestación comenzará a las 11:00 en la Plaza de España, indicándose el recorrido, con finalización en Concepción Arenal, delante del edificio de la Xunta a las 12:30 horas". La Subdelegación del Gobierno en Pontevedra respondió, entre otras cosas, "que, en la actualidad, el Real Decreto 463/2020, de 14 de marzo, por el que se declara el estado de alarma para la gestión de la situación de crisis sanitaria ocasionada por el Covid-19, no contempla, entre las actividades excepcionadas de la limitación general para circular, los desplazamientos con el fin expuesto en su comunicación".

${ }_{10}$ Se ocupan de esta resolución, ARNALDO ALCUBILLA, E. "Salus populi est lex, sed lex superior est constitutio. El ejercicio del derecho de manifestación en el estado de alarma", Diario La Ley; BILBAO UBILLOS, J. M. "La libertad de reunión y manifestación en tiempos de pandemia" en BIGLINO CAMPOS, P. y DURÁN ALBA, J. F. (Dirs.), Los efectos horizontales de la COVID sobre el sistema constitucional,...; ITUREN-OLIVER, A./ESTEVE-SEGARRA, A. "EI ejercicio del derecho de manifestación (sindical o no) durante la pandemia por el COVID-19", Trabajo y Derecho. Monográfico 12/2020,..., y RODRÍGUEZ-PIÑERO y BRAVO-FERRER, M. "Estado de alarma y derecho de manifestación del sindicato", Derecho de las relaciones laborales... 
demanda una respuesta inmediata del Tribunal, la sala ha estimado pertinente formular un análisis liminar de la verosimilitud de la lesión del derecho invocado. Si en ese examen previo, sin intervención de las partes ni del ministerio fiscal, pudieran apreciarse indicios de lesión, la eventual admisión a trámite exigiría la adopción de las medidas cautelares solicitadas por la parte porque, de no hacerse así, como bien indica la recurrente en amparo, se habría perdido el objeto del recurso de amparo que es, como ha quedado expresado en los antecedentes, la celebración de una concreta manifestación, en un día muy determinado: el 1 de mayo de 2020.

En un supuesto tan particular como este, el pronunciamiento de fondo confluye con la demanda cautelar de tal modo que es imposible desvincular uno de la otra. A diferencia de lo que ha sucedido en el ejemplo comparado que aporta la sentencia del Tribunal Constitucional Federal Alemán dictada el 15 de abril de 2020 (1 BvR 828/20), no nos pronunciaremos aquí sobre las medidas cautelares que, insistimos en ello, no son separables del pleito principal como sí lo eran en el supuesto conocido por el Tribunal Constitucional Federal Alemán que se limita, en su citado y bien conocido pronunciamiento, a devolver el asunto a la autoridad administrativa para que, con una adecuada intelección del derecho de manifestación, adopte una decisión diversa que permita compatibilizar el ejercicio del derecho de reunión en lugar de tránsito público y la garantía de la salud pública. No es el caso que se da en el supuesto de hecho planteado en el presente recurso de amparo porque la manifestación del 1 de mayo, conmemorativa de una determinada efeméride, no puede ser celebrada en otra fecha, de modo que no existe margen temporal que permita devolver el asunto a la autoridad competente para que adopte una decisión diversa".

Es llamativo también que se dediquen 4 de las 15 páginas de los fundamentos a analizar si concurre la exigencia prevista en el artículo 50.1.b de la Ley Orgánica del Tribunal Constitucional (LOTC).

$\mathrm{Y}$ es destacable porque, efectivamente, el TC concluye que sí concurre, en concreto:

"el supuesto g) de especial trascendencia constitucional del FJ 2 de la STC 155/2009, porque el supuesto planteado en el recurso de amparo 
trasciende del caso concreto ya que plantea una cuestión jurídica de relevante y general repercusión social o económica. No podemos olvidar que, como reconoce la recurrente, la manifestación se pretende desarrollar en el marco de una situación de pandemia global muy grave, que ha producido un gran número de afectados y de fallecidos en nuestro país, y que ha puesto a prueba a las instituciones democráticas y a la propia sociedad y los ciudadanos, en cuanto se han convertido, en conjunto, en elementos esenciales para luchar contra esta situación de crisis sanitaria y económica que afecta a todo el país, situado por mor de la misma ante una situación que, pese a no ser la primera vez que se produce (ya sufrimos, entre otras, la pandemia de 1918), sí es la primera vez que nuestra actual democracia se ha visto en la necesidad de enfrentarse ante un desafío de esta magnitud y de poner en marcha los mecanismos precisos para hacerle frente.

Ante esta situación es importante el pronunciamiento de este Tribunal por la repercusión que la celebración de esta o de otras manifestaciones con ocasión de la señalada fecha del 1 de mayo que se puedan pretender celebrar, puedan tener sobre el conjunto de la sociedad, especialmente sobre la salud de los ciudadanos, llevando a cabo un análisis de los contenidos del real decreto de declaración del estado de alarma y de su alcance desde la perspectiva constitucional, especialmente en cuanto al ejercicio de los derechos fundamentales, ya que puede establecer pautas importantes en la interpretación y aplicación de las distintas previsiones de aquella norma, en tanto que intérprete supremo de la normal fundamental, que resulten provechosas para el conjunto de la sociedad. Lo que también se puede traducir en la enunciación de criterios de actuación que sean importantes en el desarrollo del proceso de desescalada que está iniciando el Gobierno. Es innegable, en suma, la notoria repercusión que este asunto tiene en el conjunto de la sociedad española" (FJ 2).

Bastaría, en principio, este párrafo para seguir adelante con el recurso y entender que concurre esa especial relevancia constitucional, pero la Sala Primera hace previamente una extensa serie de consideraciones que parecen ajenas a lo que está tratando en esa parte del Auto, pues entra a recordar su jurisprudencia no sobre la especial trascendencia constitucional sino "en relación con el ejercicio de los derechos de reunión y manifestación, a través 
de la cual este Tribunal ha establecido criterios muy claros en cuanto a los presupuestos para el ejercicio de tales derechos, los límites y restricciones que pueden imponerse a los mismos, especialmente cuando colisionan con otros derechos o con la protección de otros valores constitucionales, así como las garantías que deben presidir tanto su ejercicio como la posibilidad de introducir modificaciones o limitaciones al mismo y, especialmente, cuando se trata de impedirlo".

EI TC resume a continuación lo dicho en la STC 66/1995, de 8 de mayo, y en las SSTC 301/2006, de 23 de octubre, 170/2008, de 15 de diciembre, y $96 / 2010$, de 15 de noviembre y todo este arsenal jurisprudencial viene a cuento "pues de lo que se trata es de identificar ad casum la noción de "orden público" con peligro para las personas, como elemento que ha servido para prohibir la celebración de la manifestación comunicada".

Ya hemos dicho que esta exposición es más bien propia de una sentencia en la que se está analizando si se vulneró un derecho fundamental reclamado en un recurso de amparo admitido a trámite, cosa que -ya se ha dicho- aquí no ocurrió. En todo caso, a nuestro juicio, encajaría mejor en el siguiente apartado del Auto donde se analiza la eventual adopción de medidas cautelares y la necesidad de una "respuesta inmediata del Tribunal", que acude al derecho comparado pero, en parte, para apartarse de él: cita la resolución del Tribunal Constitucional Federal Alemán dictada el 15 de abril de 2020 (1 BvR 828/20) antes de concluir, como ya hemos visto antes, que no cabe adoptar una similar (que la autoridad administrativa adopte una nueva resolución que compatibilice el derecho de reunión y la protección de la salud) "porque la manifestación del 1 de mayo, conmemorativa de una determinada efeméride, no puede ser celebrada en otra fecha, de modo que no existe margen temporal que permita devolver el asunto a la autoridad competente para que adopte una decisión diversa".

Sí acoge nuestro TC la doctrina del alemán en otra resolución de 7 de abril para justificar la inviabilidad de adoptar medidas cautelares en este caso, aprovechando para apuntarla con ella su decisión de inadmisibilidad.

En la última parte del Auto, el TC analiza, en la línea ya dicha de una sentencia desestimatoria, "la eventual lesión del derecho fundamental invocado (derecho de manifestación del art. $21 \mathrm{CE}$ )". Y comienza recordando que "para que los poderes públicos puedan incidir en el derecho de reunión constitucionalmente 
garantizado, ya sea restringiéndolo, modificando las circunstancias de su ejercicio, o prohibiéndolo incluso, es preciso..., que existan razones fundadas, lo que implica una exigencia de motivación de la resolución correspondiente".

El TC admite que la resolución de la Subdelegación del Gobierno "es abiertamente ambigua y ni siquiera deja totalmente clara la prohibición, [pero] no puede negarse que existe motivación suficiente en la Sentencia de la Sección $1^{\text {a }}$ de la Sala de lo Contencioso Administrativo del Tribunal Superior de Justicia de Galicia de 28 de abril de 2020. Cualquier defecto de motivación de la resolución administrativa, por tanto, habría quedado subsanado por la extensa motivación del órgano judicial”.

Como ha dicho Bilbao Ubillos, se trata de una "afirmación ciertamente sorprendente, porque, de acuerdo con la doctrina del propio Tribunal, es la Administración la que debe motivar sus actos -de forma más intensa aun cuando afectan al ejercicio de un derecho fundamental- y ese déficit de motivación no puede ser suplido por los tribunales que tienen que controlar precisamente si resulta o no suficiente" ${ }^{\prime 1}$.

A continuación, el TC declara que "la discusión sobre si el decreto de declaración del estado de alarma supone o no, de facto, y por derivación de la limitación de la libertad deambulatoria del art. 19 CE, una limitación excesiva o incluso una suspensión del derecho de manifestación no puede ser abordada, ni siquiera a efectos dialécticos en este momento procesal, ni siquiera en este recurso de amparo".

En suma, el TC deja de lado, como también hizo el TSJ de Aragón, el Decreto $463 / 2020$, por el que se declara el estado de alarma para la gestión de la situación de crisis sanitaria ocasionada por el COVID-19, en particular su artículo 7, y pasa a estudiar si la prohibición de la manifestación encaja en el artículo $21 \mathrm{CE}$. $\mathrm{Y}$ lo hace remitiéndose, textualmente, a "una constante jurisprudencia constitucional, a la que ya hemos hecho referencia extensa en el FJ 2" sobre el carácter limitado de los derechos fundamentales en general y de la libertad de reunión en particular.

Pero en lugar de seguir con la interpretación del artículo 21, especialmente con la parte que alude a la prohibición de reuniones "cuando existan razones fundadas de alteración del orden público, con peligro para personas o bienes",

$\overline{11}$ Ob. cit., p. 11; en el mismo sentido, ARNALDO ALCUBILLA ob. cit., p. 7. 
el TC acude a los artículos 15 (derecho a la vida y a la integridad física) y 43 CE (derecho a la salud) y nos dice que:

"en el estado actual de la investigación científica, cuyos avances son cambiantes con la evolución de los días, incluso de las horas, no es posible tener ninguna certeza sobre las formas de contagio, ni sobre el impacto real de la propagación del virus, así como no existen certezas científicas sobre las consecuencias a medio y largo plazo para la salud de las personas que se han visto afectadas en mayor o menor medida por este virus. Ante esta incertidumbre tan acentuada y difícil de calibrar desde parámetros jurídicos que acostumbran a basarse en la seguridad jurídica que recoge el art. 9.3 de la Constitución, las medidas de distanciamiento social, confinamiento domiciliario y limitación extrema de los contactos y actividades grupales, son las únicas que se han adverado eficaces para limitar los efectos de una pandemia de dimensiones desconocidas hasta la fecha. Desconocidas y, desde luego, imprevisibles cuando el legislador articuló la declaración de los estados excepcionales en el año 1981. En todo caso, parece obvio que la prohibición de celebrar la manifestación, que se deriva claramente de la resolución judicial impugnada, guarda una relación lógica y de necesidad evidente con la finalidad perseguida por esa misma interdicción: evitar la propagación de una enfermedad grave, cuyo contagio masivo puede llevar al colapso de los servicios públicos de asistencia sanitaria. La adecuación entre la finalidad pretendida por la limitación y la herramienta jurídica empleada en este caso, no parece por tanto inexistente".

EI TC, en su juicio de proporcionalidad de la medida prohibitiva sobre el que enseguida volveremos, añade que "no se prevén por los organizadores medidas de control de la transmisión del virus específicas, ni destinadas a compensar la previsible concentración de automóviles que podría producirse si existiera una masiva respuesta a la convocatoria, "que el itinerario elegido por los convocantes supone ocupar durante varias horas [en teoría hora y media] la vía principal de circulación automovilística en Vigo, dividiendo la ciudad en dos $y$, eventualmente, limitando el acceso a los hospitales que se encuentran en la zona alta de la ciudad de las personas que viven en la zona más cercana a la costa" y, más abajo, que "en una situación de alerta sanitaria, la libre circulación de los servicios de ambulancias o urgencias médicas, y el libre acceso a los hospitales es un elemento a tener en cuenta a la hora de valorar 
la proporcionalidad de la limitación de ejercicio del derecho aquí invocado. Y teniéndolo en cuenta en este caso la medida restrictiva puede tenerse como proporcionada. El impacto de la infección el covid-19 en la ciudad de Vigo tampoco es un dato despreciable a la hora de formular el juicio de proporcionalidad que nos planteamos...".

En relación con estas argumentaciones cabe, si no objetar ${ }^{12}$, sí, cuando menos, precisar lo siguiente: los promotores ofrecen una modalidad de manifestación que puede ser discutible pero, según la Ley Orgánica 9/1983, de 15 de julio, reguladora del derecho de reunión, "si la autoridad gubernativa considerase que existen razones fundadas de que puedan producirse alteraciones del orden público, con peligro para personas o bienes, podrá prohibir la reunión o manifestación o, en su caso, proponer la modificación de la fecha, lugar, duración o itinerario de la reunión o manifestación" (art. 10), es decir, si la Subdelegación del Gobierno en Pontevedra considera que las propuestas de los organizadores son insuficientes puede proponer medidas que las complementen: por ejemplo, que la manifestación dure media hora y no hora y media o que el recorrido sea distinto y no limite el acceso a los hospitales; sin embargo, la autoridad administrativa no hace ningún esfuerzo por tratar de hacer efectivo un derecho tan relevante como el de reunión en una fecha tan importante como la del 1 de mayo. $Y$ eso que la entidad convocante se había mostrado abierta a adoptar más medidas ${ }^{13}$.

Al respecto, hay que recordar que la prohibición constituye, como es lógico si partimos del principio de efectividad de los derechos fundamentales, el "último recurso", debiendo antes contemplarse, como prevé la Ley Orgánica 9/1983, la opción de proponer a los promotores modificaciones que puedan hacer compatible el derecho de reunión con otros derechos, en la línea, por ejemplo, de lo resuelto por la citada sentencia del TSJ de Aragón.

\footnotetext{
12 BILBAO UBILLOS concluye que "en un país en el que se han celebrado cientos de manifestaciones masivas por el centro neurálgico de las ciudades, resulta como mínimo exagerado invocar el peligro de un colapso circulatorio con inmovilización prolongada de vehículos que imposibilite el acceso a determinadas zonas o la prestación de servicios esenciales como ambulancias, bomberos, policía o urgencias médicas (SSTC 66/1995 y 59/1990), ante la convocatoria de una modestísima caravana por una organización sindical minoritaria con escasa capacidad de movilización. Ese escenario de grave obstrucción del tráfico que puede llegar a dividir la ciudad mediante una barrera infranqueable no es creíble. $Y$ menos con una población confinada"; ob. cit., p. 13.

${ }^{13}$ Así, en el punto sexto de la convocatoria se decía que, "entendendo a gravidade da situación que vivimos a CUT opta po la manifestación rodada cun manifestante en cada auto e debidamente protexidos e identificados polo sindicato, e atendendo a calquera outra indicación que se nos faga dende esta subdelegacion ou as autoridades sanitarias".
} 
Pero es que el propio TC en su Auto de inadmisión no hace un auténtico juicio de proporcionalidad sobre la medida adoptada por la Subdelegación del Gobierno y avalada por el TSJ de Galicia tal y como el propio TC lo ha configurado:

“...en primer lugar, que sea idónea para alcanzar el fin constitucionalmente legítimo perseguido por ella...; en segundo lugar, que sea necesaria o imprescindible para ello, esto es, que no existan otras medidas menos gravosas que, sin imponer sacrificio alguno de derechos fundamentales o con un sacrificio menor, sean igualmente aptas para dicho fin (juicio de necesidad); y, por último, que se deriven de su aplicación más beneficios o ventajas para el interés general que perjuicios sobre otros bienes o intereses en conflicto 0 , dicho de otro modo, que el sacrificio impuesto al derecho fundamental no resulte desmedido en relación con la gravedad de los hechos y las sospechas existentes (juicio de proporcionalidad en sentido estricto)" (por ejemplo, STC 70/2002, de 3 de abril, FJ 10).

En el caso que nos ocupa el TC parece obviar las dos primeras exigencias de este principio y va directamente a la tercera: sin duda la protección de la vida, de la salud y del funcionamiento del sistema sanitario son más relevantes para el interés general que la prohibición de una concreta manifestación pero ¿es la prohibición de una manifestación que se celebrará a bordo de vehículos, en el contexto de concentraciones de personas en centros de trabajo y en supermercados, la media adecuada para esa finalidad? Y, sobre todo, ¿es la prohibición la medida mínima imprescindible en el sentido de que no haya otra que con un sacrificio menor sea apta para el mismo fin?

\section{LAS MANIFESTACIONES CONVOCADAS PARA EL 23 DE MAYO DE 2020}

El partido político VOX convocó 52 manifestaciones para el día 23 de mayo de 2020 para, según decía su presidente en Twitter, exigir "en las calles de una forma segura para la salud que comience la \#FaseLibertad y que dimita el Gobierno de la mentira, el paro y la miseria \#Caravana23M".

La respuesta administrativa a estas convocatorias fue, como recuerda Bilbao Ubillos, dispar: "siguiendo la pauta marcada por la Delegación del Gobierno en 
Castilla y León, las Subdelegaciones respectivas prohibieron las concentraciones en las nueve capitales de provincia de la Comunidad, que seguía entonces en la fase 0 de la desescalada, escudándose en el riesgo para la salud pública. Lo mismo hizo el Ministerio del Interior respecto de las convocadas en las cuatro capitales catalanas. Mientras que en otras Comunidades y provincias (Cantabria, Cáceres, Castellón, Ciudad Real, Cuenca, Granada, Guadalajara, A Coruña) se permitieron, sin poner traba alguna"14.

Pues bien, la respuesta jurisprudencial en este caso fue favorable al ejercicio del derecho de reunión; valgan como muestra alguna de las resoluciones de los TSJ de Castilla y León, Madrid y Cataluña.

El primero de dichos Tribunales declaró nulas de pleno derecho las resoluciones de las nueve Subdelegaciones del Gobierno en la Comunidad Autónoma por las que se prohibía "la manifestación (caravana) comunicada... para el próximo día 23 de mayo de 2020 y reconocemos el derecho de la parte recurrente a llevar a cabo dicha manifestación".

En las sucesivas sentencias, el TSJ de Castilla y León recuerda, primero, que el derecho de reunión y su vertiente del derecho de manifestación... cuando se celebra en lugares de tránsito público,... no están suspendidos por el Real Decreto 463/2020, de 14 de marzo, por el que se declara el estado de alarma para la gestión de la situación de crisis sanitaria ocasionada por el covid-19; en segundo lugar, que la regla general es, pues, el favorecimiento del derecho de reunión, que sólo debe verse exceptuado si, en el caso concreto y previa ponderación y juicio de proporcionalidad, concurren datos y circunstancias que permiten su limitación, en garantía de un interés constitucional o público superior; en tercer término, el TSJ sostiene que "no se justifican suficientemente para que se prohíba la manifestación los riesgos hipotéticos de contagio cuando la manifestación de que se trata está prevista por un tiempo muy limitado en vehículos cerrados, cuya circulación está permitida en el estado de alarma, y en bicicletas o motocicletas, cuyo uso también está permitido en el estado de alarma, y para evitar esos contagios se contempla en el escrito de comunicación del partido político demandante que se guardará la distancia oportuna, lo que comporta que debe guardarse la distancia de seguridad así como el uso de las correspondientes mascarillas"; finalmente,

${ }^{14}$ Ob. cit. p. 15. 
"las dificultades para el tráfico rodado a las que se refiere la resolución administrativa impugnada tampoco pueden servir para la prohibición de la manifestación de que se trata" (FFJJ 4, 5, 6 y 7 de la sentencia 470/2020, de 21 de mayo).

En la misma línea, el TSJ de Madrid (sentencia 214/2020, también de 21 de mayo) argumentó, en este caso en relación con una demanda presentada por el Partido Comunista de los Pueblos de España, que la concentración ha sido diseñada y programada por el promotor en términos muy específicos y adaptados a las circunstancias de salud pública en que se incardina su celebración. La propia modalidad escogida para la celebración de la reunión proyectada -concentración estática de un número máximo de 50 personas- y la minuciosidad de los anexos a la comunicación de la concentración no dejan lugar a dudas en tal sentido. De contrario no se ha acreditado, ni tan siquiera indiciariamente, que dichas medidas no alcancen el estándar de seguridad exigible según los actuales parámetros de evolución de la pandemia. Es más, un mínimo contraste pone de relieve que las medidas de seguridad implementadas llegan a ser más exigentes que las previstas con carácter general. Así, por ejemplo, la distancia de seguridad interpersonal a observar por los asistentes a la concentración, todos ellos dotados de las oportunas mascarillas y guantes, sería de tres metros cuando la Orden SND/422/2020, de 19 de mayo, por la que se regulan las condiciones para el uso obligatorio de mascarilla durante la situación de crisis sanitaria ocasionada por el covid-19 prevé, en su art. 3, una distancia de dos metros para la población en general.

Frente a tales medidas propuestas por el promotor de la concentración, por la Administración se oponen únicamente consideraciones generales en torno a la gravedad de la situación de crisis sanitaria y riesgos igualmente genéricos que podría comportar su celebración. Sin embargo, frente a una comunicación de concentración tan autolimitada, ponderada y detallada como la que nos ocupa y en las actuales circunstancias de "desescalada" a que hemos hecho mención anteriormente, resulta exigible que se expliciten de modo suficiente las razones concretas y verificables sobre las que sustentar la conclusión de que aquella reunión no resulta compatible con la salud pública y que, por ende, para su debida protección solo cabe la medida de prohibición" (FJ 11).

Finalmente, el TSJ de Cataluña (sentencias 1389 a 1392/2020, de 22 de mayo), a propósito de las manifestaciones promovidas por el partido político VOX en las capitales de provincia catalanas, concluyó (FJ 5 de la sentencia 
1389) que "cabe constatar (es un hecho notorio) que la pandemia ha remitido considerablemente, presentando la situación sanitaria, un escenario sensiblemente mejor que el analizado por el Tribunal Constitucional respecto a la ciudad de Vigo. En el contexto que acabamos de describir no parece proporcional el prohibir una manifestación en vehículos cuando resulta que, ordinariamente, las personas pueden pasear por la ciudad durante franjas horarias generosas, sin límite numérico, bajo la única condición de hacerlo guardando las distancias y con mascarilla. Nada indica que la manifestación en vehículos que pretende realizar el partido político VOX pueda traducirse en perjuicios significativos para la vida o la salud de las personas; y admitir una prohibición basada en meras conjeturas supondría una quiebra clara del derecho fundamental de reunión y manifestación pacífica, amén de un peligroso precedente".

Este conjunto de resoluciones, que en varios de los casos contienen referencias a varias de las sentencias citadas (las del TSJ de Cataluña incluyen una extensa remisión a las sentencias de los TSJ de Castilla y León y Madrid), contienen una argumentación similar y, a nuestro juicio, "constitucionalmente adecuada": por decirlo en pocas palabras, todas ellas destacan la importancia que corresponde al derecho fundamental de reunión en una sociedad democrática, con exhaustivas citas de jurisprudencia del TEDH y del TC; reiteran que dicho derecho fundamental no está limitado, con carácter general, por la declaración de un estado de alarma; que, no obstante el deber de favorecer su ejercicio que corresponde a los poderes públicos, ese derecho está sujeto a límites en aras a la protección de otros derechos y bienes constitucionalmente protegidos; que, en todo caso, corresponde a la autoridad administrativa que pretende limitar o prohibir un concreto ejercicio del derecho de reunión justificar suficientemente los eventuales riesgos para -en este contexto de pandemia- la salud pública y la vida e integridad de las personas, debiendo optarse, siempre que sea posible, por las medidas que, siendo adecuadas para garantizar esos otros derechos, minimizan su impacto en el ejercicio del derecho que nos ocupa.

Ya se ha apuntado, por otra parte, y en la línea con esta doctrina jurisprudencial y académica, que el vigente (en el momento de finalizar estas líneas, diciembre de 2020) Real Decreto 926/2020, de 25 de octubre, por el que se declara el estado de alarma para contener la propagación de infecciones causadas por el SARS-CoV-2, prevé, expresamente, que "las 
reuniones en lugares de tránsito público y las manifestaciones realizadas en ejercicio del derecho fundamental regulado en el artículo 21 de la Constitución podrán limitarse, condicionarse o prohibirse cuando en la previa comunicación presentada por los promotores no quede garantizada la distancia personal necesaria para impedir los contagios" (artículo 7.3).

\section{BREVES CONSIDERACIONES SOBRE LA LIMITACIÓN DE LA PERMANENCIA DE GRUPOS DE PERSONAS EN ESPACIOS PÚBLICOS Y PROVADOS DURANTE EL ESTADO DE ALARMA}

Ese mismo Real Decreto 926/2020 prevé en los números 1 y 2 del artículo 7 que:

"1. La permanencia de grupos de personas en espacios de uso público, tanto cerrados como al aire libre, quedará condicionada a que no se supere el número máximo de seis personas, salvo que se trate de convivientes y sin perjuicio de las excepciones que se establezcan en relación a dependencias, instalaciones y establecimientos abiertos al público. La permanencia de grupos de personas en espacios de uso privado quedará condicionada a que no se supere el número máximo de seis personas, salvo que se trate de convivientes.

En el caso de las agrupaciones en que se incluyan tanto personas convivientes como personas no convivientes, el número máximo a que se refiere el párrafo anterior será de seis personas.

2. La autoridad competente delegada correspondiente podrá determinar, en su ámbito territorial, a la vista de la evolución de los indicadores sanitarios, epidemiológicos, sociales, económicos y de movilidad, previa comunicación al Ministerio de Sanidad y de acuerdo con lo previsto en el artículo $13^{15}$, que el número máximo a que se refiere el apartado anterior sea inferior a seis personas, salvo que se trate de convivientes.

\footnotetext{
15 "Con la finalidad de garantizar la necesaria coordinación en la aplicación de las medidas contempladas en este real decreto, el Consejo Interterritorial del Sistema Nacional de Salud, bajo la presidencia del Ministro de Sanidad, podrá adoptar a estos efectos cuantos acuerdos procedan, incluidos, en su caso, el establecimiento de indicadores de referencia y criterios de valoración del riesgo".
} 
Asimismo, de acuerdo con lo previsto en el artículo $10^{16}$, las autoridades competentes delegadas podrán, en su ámbito territorial, establecer excepciones respecto a personas menores o dependientes, así como cualquier otra flexibilización de la limitación prevista en este artículo".

Limitaciones de este tipo ya estuvieron vigentes durante el estado de alarma acordado por el Decreto 463/2020 y tras su finalización y antes del comienzo del acordado vía Decreto 926/2020 ${ }^{17}$ y sobre las mismas surgen, cuando menos, dos cuestiones: de qué se habla, en términos jurídicos, cuando se habla de este tipo de reuniones $y$, en segundo lugar, cuál es el fundamento normativo de estas restricciones.

En relación con lo primero, tanto la CE como el CEDH parecen partir de un concepto "finalista" del derecho de reunión; así, y como ya hemos visto al comienzo de estas páginas, para el TEDH "las reuniones protegidas por el CEDH se definen por un determinado objetivo común de las personas participantes" (Navalny c. Rusia, sentencia de la Gran Sala de 15 de noviembre de 2018, § 110), que puede tener un carácter esencialmente político, social, cultural, religioso...; por su parte, el TC (STC 193/2011, de 12 de diciembre, FJ

\footnotetext{
16 "La autoridad competente delegada en cada comunidad autónoma o ciudad con Estatuto de autonomía podrá, en su ámbito territorial, a la vista de la evolución de los indicadores sanitarios, epidemiológicos, sociales, económicos y de movilidad, previa comunicación al Ministerio de Sanidad y de acuerdo con lo previsto en el artículo 13, modular, flexibilizar y suspender la aplicación de las medidas previstas en los artículos 5, 6, 7 y 8, con el alcance y ámbito territorial que determine. La regresión de las medidas hasta las previstas en los mencionados artículos se hará, en su caso, siguiendo el mismo procedimiento".

${ }_{17}$ Así, por ejemplo, el artículo 3 de la Orden SND/386/2020, de 3 de mayo, por la que se flexibilizan determinadas restricciones sociales y se determinan las condiciones de desarrollo de la actividad de comercio minorista y de prestación de servicios, así como de las actividades de hostelería y restauración en los territorios menos afectados por la crisis sanitaria ocasionada por el COVID-19, dispuso: "Contacto social en grupos reducidos. 1. Se autorizan las reuniones de hasta un máximo de diez personas. Este límite no se aplicará a personas convivientes. 2. En todo caso, durante estos contactos sociales con terceros no convivientes deberán respetarse las medidas de seguridad e higiene establecidas por las autoridades sanitarias para la prevención del COVID-19, relativas al mantenimiento de una distancia mínima de seguridad de dos metros o estableciendo medidas alternativas de protección física, de higiene de manos y etiqueta respiratoria".

Señala BILBAO UBILLOS que "si tomamos como referencia las medidas adoptadas en el marco de la Unión Europea llama la atención la disparidad de criterios. Nos encontramos, por un lado, con países que no han restringido de ningún modo el ejercicio del derecho de reunión, como Holanda, Luxemburgo, Italia o Lituania. Y por otro con Estados en los que sí se han impuesto limitaciones específicas, prohibiendo las "grandes reuniones" (Alemania o Bélgica) o fijando un número máximo de asistentes. Pero las cifras oscilan entre las 10.000 personas en las reuniones al aire libre en Austria a las 10 en España o Chipre, pasando por las 2.000 en Estonia, las 500 en Hungría, República Checa y Eslovaquia, las 100 en Croacia, los 50 de Suecia o Eslovenia, los 20 de Portugal (salvo Lisboa) o las 15 en Irlanda...", ob. cit., p. 23, nota 50.
} 
3), también ha insistido en que "el derecho de reunión... se caracteriza como una manifestación colectiva de la libertad de expresión efectuada a través de una asociación transitoria de personas que opera de manera instrumental al servicio del intercambio o exposición de ideas, de defensa de intereses o de publicidad de problemas y reivindicaciones, cuyos elementos configuradores son el subjetivo (agrupación de personas), el temporal (duración transitoria), el finalista (licitud de la finalidad) y el real u objetivo (lugar de celebración)". Así pues, parece que no toda reunión de personas en un espacio público o privado es una conducta amparada por los artículos $11 \mathrm{CEDH}$ y $21 \mathrm{CE}$.

No obstante, de la lectura de la varias veces mencionada Ley Orgánica 9/1983, reguladora del derecho de reunión, resulta que "se podrá ejercer el derecho de reunión sin sujeción a las prescripciones de la presente Ley Orgánica, cuando se trate de las reuniones siguientes: a) Las que celebren las personas físicas en sus propios domicilios. b) Las que celebren las personas físicas en locales públicos o privados por razones familiares o de amistad..."

Por tanto, las reuniones en las que inciden, limitando el número de asistentes, tanto las normas aprobadas durante el estado de alarma declarado el 14 de marzo como el propio Real Decreto 926/2020, de 25 de octubre, pueden estar amparadas por la Ley Orgánica 9/1983 pero, a su vez, las restricciones impuestas por los Decretos de estado de alarma a dichas reuniones podrían reconducirse a la medida prevista en el artículo 11.a) de la Ley Orgánica 4/1981: "limitar la circulación o permanencia de personas o vehículos en horas y lugares determinados, o condicionarlas al cumplimiento de ciertos requisitos", pero, precisamente, si es así cabría dudar de la proporcionalidad de la prohibición tajante de que dichas reuniones superen las seis personas, máxime si se trata de espacios públicos y quienes asisten cumplen las medidas preventivas ya previstas, como la que contempla el uso obligatorio de las mascarillas "en la vía pública, en espacios al aire libre y en cualquier espacio cerrado de uso público o que se encuentre abierto al público, siempre que no resulte posible garantizar el mantenimiento de una distancia de seguridad interpersonal de, al menos, 1,5 metros" (artículo 6.1.a. del Real Decreto-ley 21/2020, de 9 de junio, de medidas urgentes de prevención, contención y coordinación para hacer frente a la crisis sanitaria ocasionada por el covid-19). 